\title{
Public Awareness of Oral Cancer in Chennai, India
}

\author{
Nor Syakirah Binti Shahroom ${ }^{1 *}$
}

\section{ABSTRACT}

Oral Cancer is one of the top killer disease. It is also known as cancer of lip, tongue and other parts of the mouth. Although oral cancer is difficult to discover because it is unnoticeable during its early stages, there should be a possibility of recovery. This cancer would have the chances to be treated and prevented it there is an early diagnosis about this disease. One of the factors of Oral Cancer is due to lack of awareness and knowledge about Oral Cancer including the causes and risk factors. Therefore, a questionnaire has been given to the public around Chennai to record the awareness of the public toward Oral Cancer based on the question given.

Keywords: Oral Cancer, HPV, tobacco, alcohol

Awareness of oral cancer is an essential knowledge despite other common cancer such as lung cancer and breast cancer which are leading in men and women. World Health Organization (WHO) stated that oral cancer is prevalent in South East Asia and Asia countries such as Taiwan, India, Bangladesh and Sri Lanka(Stewart \& Kleihues, 2003). Based on the previous research done, in spite of lack of awareness of oral cancer, the risk factors habit also play an important role in the development of oral cancer. Oral cancer are squamous cell carcinomas which are presence in the oral mucosa(McLeod, Saeed, \& Ali, 2005). However, it is believed that oral cancer is remediable(Organization, 1984). Early diagnosis of oral cancer is quite possible with the advance technology, as well as, easily accessible and detectable through self-examination of the symptoms (Warnakulasuriya et al., 1999). Delay in the treatment or late diagnosis may lower the rate of survival of patients with oral cancer (Khandekar, Bagdey, \& Tiwari, 2006). This may increase the development of tumour which prevent it from curing or the treatment may be costly for some patients.

Tobacco, smoking and alcohol consumption are the most common risk factors of oral cancer which contribute to $90 \%$ of the factor of oral cancer (Stewart \& Kleihues, 2003). Tobacco along with alcohol consumption will multiplies the risk (Pelucchi, Gallus, Garavello, Bosetti, \& La Vecchia, 2006). Tobacco production in India is the second largest in the world which has

\footnotetext{
${ }^{1}$ IBDS Saveetha Dental College \& Hospital, Saveetha University, Chennai, Tamil Nadu, India *Responding Author

(C) 2016 I S Nor; licensee IJIP. This is an Open Access Research distributed under the terms of the Creative Commons Attribution License (http://creativecommons.org/licenses/by/2.0), which permits unrestricted use, distribution, and reproduction in any Medium, provided the original work is properly cited.
} 
approximately 274.9 million tobacco users (Agrawal, Pandey, Jain, \& Maitin, 2012). Thus, it is possible that India population is exposed to tobacco and if it is uncontrollable, consumption of tobacco may be the first reason of oral cancer.

Therefore, this study was aimed to determine the level of awareness of oral cancer in Chennai, India through questionnaires given randomly among the population. The objective of this study is to expose the knowledge of oral cancer including the risk factors, symptoms and treatments to the people to make sure that the percentage of oral cancer in India may be reduced to a satisfying percentage.

\section{MATERIALS AND METHOD}

This study was conducted throughout Chennai. Questionnaires were given randomly to the public who were willing to participate. Both English and Tamil language questionnaires were prepared. The questions given were related to the demographic (age and gender), risk factors and knowledge on oral cancer. The age of the participants were from 16 to 50 and above. This study was done in two weeks.

A total of 101 questionnaires were circulated throughout Chennai. 20 participants were chosen for each range of age except for 20-29 years old. Therefore, age 16-19 years were 20 participants, 20-29 years were 21 participants, 30-39 years were 20 participants, 40-49 years were 20 participants and 50 and above years were also 20 participants. A total of 13 questions with choices of yes or no regarding oral cancer were calculated and recorded.

\section{Table1: Questionnaire on public awareness of Oral Cancer in Chennai.}
1. Age: (a) $16-19$
(b) 20-29
(c) $30-39$
(d) $40-49$
(e) 50 and above

2. Gender: Male Female

3. Have you came across anyone with oral cancer?

4. Do you think tobacco has an effect on oral cancer?

5. Does cigarette smoking lead to oral cancer?

6. Does consumption of alcohol lead to oral cancer?

7. Does Human papilloma virus (HPV) infection lead to oral cancer?

8. Which gender have the highest risk to get oral cancer?

9. What age does the risk of oral cancer is the highest?

10. Can oral cancer be treated?

11. Can good oral hygiene prevent oral cancer?

12. Does early diagnosis of oral cancer prevent it from getting worse?

13. Can a campaign or seminar help increase the awareness of Oral Cancer? 


\section{RESULTS}

Among of 101 respondents, 42 (41.6\%) were male and 59 (58.4\%) were female. Among them, 39 respondents (38.6\%) had come across anyone with Oral Cancer either their family members or friends and 62 have not come across.

There are four questions related to the risk factors which were the consumption of tobacco, alcohol, cigarette smoking and Human papilloma virus (HPV) infection. More than 80\% of respondents were aware that tobacco and cigarette smoking leads to Oral Cancer which both recorded 84 (83.2\%) respondents each. 17 (16.8\%) respondents believed that tobacco and cigarette smoking does not give any effect to Oral Cancer. Besides, 60.4\% respondents thought that consumption of alcohol will lead to Oral Cancer whereas 36.9\% knew that the consumption of alcohol did not lead to Oral Cancer except if it is taken along with tobacco. Among the respondents, 62.4\% were aware of a sexually transmitted infections, Human Papilloma virus (HPV) may lead to Oral Cancer and $37.6 \%$ were not aware, acknowledge or heard about this virus.

Apart from that, questions on high risk gender and age were arise. Most of the respondents select male which have a high risk to get Oral Cancer compared to women which were $84.1 \%$. More than half (52.5\%) of the respondents thought that Oral Cancer is common among elderly which age 50 and above.

Based on the awareness of Oral Cancer questions, it showed a satisfying results as all the questions related, achieved more than $70 \%$. 79 respondents (78.2\%) believed that Oral Cancer can be treated and almost $90 \%$ aware that Oral Cancer can be prevented from getting worse through early diagnosis. Three quarter of the respondents correctly chose that good oral hygiene may reduce the risk factor of getting Oral Cancer. Last but not least, 86\% of respondents suggested that campaign or seminar help to increase the awareness of Oral Cancer.

\section{Table 2: Percentage distribution based on the questions.}

\begin{tabular}{|c|c|c|}
\hline \multirow[t]{2}{*}{ Questions } & \multicolumn{2}{|c|}{ Percentage (\%) } \\
\hline & Yes & No \\
\hline $\begin{array}{l}1 . \quad \text { Gender: } \\
\text { Male } \\
\text { Female }\end{array}$ & $\begin{array}{l}41.6 \% \\
58.4 \%\end{array}$ & \\
\hline 2. $\quad$ Have you came across anyone with oral cancer? & $38.6 \%$ & $61.4 \%$ \\
\hline 3. Do you think tobacco has an effect on oral cancer? & $83.2 \%$ & $16.8 \%$ \\
\hline
\end{tabular}

(C) The International Journal of Indian Psychology, ISSN 2348-5396 (e)| ISSN: 2349-3429 (p) | 35 
Public Awareness of Oral Cancer in Chennai, India

\begin{tabular}{|c|c|c|}
\hline 4. $\quad$ Does cigarette smoking lead to oral cancer? & $83.2 \%$ & $16.8 \%$ \\
\hline Does consumption of alcohol lead to oral cancer? & $60.4 \%$ & $39.6 \%$ \\
\hline 6. $\quad$ Does Human papillomavirus (HPV) infection lead to oral cancer? & $62.4 \%$ & $37.6 \%$ \\
\hline $\begin{array}{l}7 . \quad \text { Which gender have the highest risk to get oral cancer? } \\
\text { Male } \\
\text { Female }\end{array}$ & $\begin{array}{l}84.2 \% \\
15.8 \%\end{array}$ & \\
\hline $\begin{array}{l}8 . \quad \text { What age does the risk of oral cancer is the highest? } \\
\text { Below } 50 \\
\text { Above } 50\end{array}$ & $\begin{array}{l}47.5 \% \\
52.5 \%\end{array}$ & \\
\hline Can oral cancer be treated? & $78.2 \%$ & $21.8 \%$ \\
\hline 10. Can good oral hygiene prevent oral cancer? & $75.2 \%$ & $24,8 \%$ \\
\hline 11. Does early diagnosis of oral cancer prevent it from getting worse? & $87.1 \%$ & $12.9 \%$ \\
\hline Can a campaign or seminar help increase the awareness of Oral Cancer? & $86.1 \%$ & $13.9 \%$ \\
\hline
\end{tabular}

\section{DISCUSSION}

The awareness of Oral Cancer among public in Chennai is high as most of them can identify the risk factors of Oral Cancer very well. Tobacco and cigarette smoking are the main risk factors of Oral Cancer in India. Especially tobacco, it can be taken in any form such as chewing or sucking. Besides, Human papillomavirus (HPV) is a sexually transmitted infections which is common among women. It is believed that this virus may be associated with Oral Cancer especially among the smokers (Herrero et al., 2003).

Although there were some misconception among them, for example some respondents thought that Oral Cancer cannot be treated and early diagnosis cannot prevent Oral Cancer from getting worse, it still can be improved. Education seminar or campaigns about awareness of Oral Cancer can be conducted among society in public places. Many alternatives can also be taken in spite of campaigns or seminar. For example, brochure and as well as newspaper can be distributed to the public which explain about Oral Cancer and its risk factors, harmful effects, ways of diagnosis and treatment(Elango et al., 2009). 


\section{Public Awareness of Oral Cancer in Chennai, India}

Furthermore, the awareness of Oral Cancer should be built up among the younger generations as they are the future generations of the world. Thus, social networking could be the best way to expose the young generations towards Oral Cancer.

\section{CONCLUSION}

This study shows that the awareness of Oral Cancer in public around Chennai is convincing among teenagers until senior citizens. Most of the public were aware of the risk factors that will cause Oral Cancer rapidly especially among smokers. However, there are still people which are lacking on the knowledge specifically in the rural areas. Therefore, initiatives should be taken to improve the awareness of Oral Cancer throughout Chennai.

\section{REFERENCES}

1. Agrawal, M., Pandey, S., Jain, S., \& Maitin, S. (2012). Oral cancer awareness of the general public in Gorakhpur city, India. Asian Pacific Journal of Cancer Prevention, 13(10), 5195-5199.

2. $\quad$ Elango, J. K., Sundaram, K. R., Gangadharan, P., Subhas, P., Peter, S., Pulayath, C., \& Kuriakose, M. A. (2009). Factors affecting oral cancer awareness in a high-risk population in India. Asian Pac J Cancer Prev, 10(4), 627-630.

3. Herrero, R., Castellsagué, X., Pawlita, M., Lissowska, J., Kee, F., Balaram, P., . . Pintos, J. (2003). Human papillomavirus and oral cancer: the International Agency for Research on Cancer multicenter study. Journal of the National Cancer Institute, 95(23), 17721783.

4. Khandekar, S., Bagdey, P., \& Tiwari, R. (2006). Oral cancer and some epidemiological factors: A hospital based study. Indian J Community Med, 31(3), 157-159.

5. McLeod, N., Saeed, N., \& Ali, E. (2005). Oral cancer: delays in referral and diagnosis persist. British dental journal, 198(11), 681-684.

6. Organization, W. H. (1984). Control of oral cancer in developing countries. Bull World Hlth Org, 62, 817-830.

7. Pelucchi, C., Gallus, S., Garavello, W., Bosetti, C., \& La Vecchia, C. (2006). Cancer risk associated with alcohol and tobacco use: focus on upper aero-digestive tract and liver. Alcohol Research \& Health, 29(3), 193-199.

8. Stewart, B., \& Kleihues, P. (2003). WHO Cancer Report. Lyon, France: IARC, 215-222.

9. Warnakulasuriya, K., Harris, C., Scarrott, D., Watt, R., Gelbier, S., Peters, T., \& Johnson, N. (1999). An alarming lack of public awareness towards oral cancer. British dental journal, 187(6), 319-322.

How to cite this article: S Nor (2016), Public Awareness of Oral Cancer in Chennai, India, International Journal of Indian Psychology, Volume 3, Issue 3, No. 10, DIP: 18.01.175/20160303, ISBN: 978-1-365-19879-3 